\title{
Muerte y larga duración histórica: Hacia el sentido de la muerte en el siglo XXI. Una propuesta desde la teoría de la historia
}

\author{
Daniel Ovalle Pastén ${ }^{1}$
}

"Según creo, el historiador no está condenado a carecer de voz frente al discurso considerado solitario del filósofo que habla de la muerte".

Paul Ricoeur ${ }^{2}$

El estudio sistemático de la historicidad de la muerte por parte de los historiadores data de la segunda mitad del siglo XX. En especial desde los años setenta e impulsados particularmente desde la antropología y la historiografía francesa, destacan los estudios de las actitudes ante la muerte en clásicos como Philippe Ariès y Michel Vovelle. Esta fue una suerte de fuerza intelectual que llegó a la historiografía latinoamericana donde vimos surgir, en los años noventa, una serie de estudios que hoy son referencia obligada. Baste nombrar para el caso de México a Gisela von Wobeser y para Chile el de María Eugenia Horvitz, Isabel Cruz y Marco Antonio León. Toda esta corriente historiográfica, que se ha visto beneficiada por aportes desde otras disciplinas, ha dado buena cuenta de procesos de larga y corta duración entre los siglos XVI y XIX, todos ellos relacionados con la vida religiosa -" poner el alma en carrera de salvación" , prácticas de la vida material (alojadas en testamentos), vida económica (fundación de capellanías, cofradías, etc.), imaginarios (la vida eterna, purgatorio, infierno), emociones (miedo a la condenación, esperanza de la salvación eterna) - y el posterior proceso de secularización de la vida, esa separación de las esferas públicas y privadas en la cual la creencia en el "más allá" comenzó a ser relegada a la conciencia privada de cada individuo, donde las políticas públicas e ilustradas y los avances médicos y tecnológicos fueron minando el conjunto de prácticas y creencias que hacían de la muerte

Chileno. Académico de la Universidad Andrés Bello y Universidad de Valparaíso. Candidato a Doctor en Historia, Universidad de Chile. Este trabajo es fruto de la ponencia presentada en las XXI Jornadas de Historia de Chile, noviembre 2015. Agradezco la lectura crítica de la historiadora María Eugenia Horvitz y el patrocinio de la Beca CONICYT-PCHA/Doctorado Nacional/2013-21130188. E-mail: ovalle.daniel@gmail.com

2 (2010: 20). 
un fenómeno religioso y público. Satisfactorias respuestas tenemos para este proceso complejo, todas ellas dispuestas a explicar la historicidad del morir desde la sociedad barroca hasta el asentamiento de la modernidad, sea esta realidad para el siglo XVIII en Europa o un siglo después en Latinoamérica. Con todo, es necesario decir que carecemos de historias de la muerte próximas a nuestra contemporaneidad. Si bien el proceso religioso ha mutado, esta no puede ser la respuesta para el vacío historiográfico que se observa.

Consecuencia de ello ha sido que el siglo XX ha quedado relegado, me refiero en especial a las formas y sentidos del morir en aquello que Alain Touraine llama las sociedades postindustriales, sociedades mucho más globalizadas que las del XIX, y con características distintas. Una segunda modernidad, líquida en palabras de reciente fallecido Zygmunt Bauman, donde la confianza moderna del sujeto que parecía ser comprendido desde la totalidad hegeliana, ha quedado a medias, fragmentada. La para algunos Ilamada posmodernidad triunfante desde Nietzsche en adelante fisura la confianza en la filosofía de la conciencia y nos sumerge en una diáspora de individualidades a veces seguras de sí, otras veces marcadas por el trauma y el dolor, lugar este último donde el psicoanálisis ha dado muestras de vías de comprensión.

Con todo, luego del giro lingüistico, sabemos que el lenguaje precede a la experiencia y con ello podemos problematizar que lo que narramos es la experiencia temporal: sincrónica y diacrónica. La muerte y su historicidad es hablar del thánatos, pues nadie que la experimente puede venir a contarnos qué es lo que se vive luego de ella: ¿hay experiencia después de morir? Esta es una pregunta aporética, no incumbe a la historiografía ni a las ciencias sociales. Sí la serie de relaciones materiales y simbólicas que la rodean en el tiempo y espacio. Por ello, la historia de la muerte necesita seguir siendo estudiada, tanto en tiempos remotos como desde la historia reciente, desde la contemporaneidad, incluso desde aquello que siendo contemporáneo no lo es: en palabras de Hugo Vezetti como formación de memoria, o, como le gusta decir a cierta historiografía francesa, desde la contemporaneidad de lo no contemporáneo.

Lo que sigue se plantea desde esta posición epistemológica a razón de observar un silencio en la historiografía de la muerte con respecto al tiempo presente. La historiografía no ha entrado de lleno en la historicidad de la muerte contemporánea, y con ello expreso las formas del morir desde generaciones próximas al sujeto observador, la denominada "historia vivida" (Aróstegui, 2004: 52-102), que no es otra que el trabajo metodológico del pasado, pero vivido en algún grado por el mismo historiador, en palabras de Lacapra, donde el historiador es un "testigo secundario" (Lacapra, 2009: 35).

De esta manera, sabemos del morir barroco, también del morir moderno, pero poco y nada de las actitudes ante la muerte en los últimos decenios desde 
la historiografía (la sociología ha hecho bastante) en el paso del corto siglo XX al XXI. La historia del tiempo presente nos puede ayudar, pero aquello no es objeto directo de este trabajo (no encontrará el lector un trabajo de fuentes), pero sí establecer parámetros teóricos para su estudio historiográfico y así promover la historicidad del morir para la historiografía del tiempo presente. Lo que sigue entiende que para todo estudio del morir contemporáneo resulta fundamental -desde la teoría historiográfica- el establecimiento de la historicidad como problema temporal, no cronológico, en otras palabras: como interpretación social del tiempo.

Entienda bien el lector, este es un ensayo de apertura que está lejos de ser un trabajo sistemático, que se posiciona desde la teoría historiográfica, por lo tanto, desde discusiones de sus formas operativas o lógicas de investigación disciplinar asociadas a los marcos sociales que las abrigan, lo que recientemente Herman Paul calificó de "llamadas del pasado" (Paul, 2015: 30-42).

Me gustaría, en un primer momento, justificar lo que sigue desde un argumento metodológico, para luego entrar en su desarrollo, planteando una hipótesis: ¿Es viable el estudio en larga duración histórica ya entrado el siglo XXI? El año 2014 la Universidad de Cambridge publicó en acceso abierto el libro The History Manifesto de los autores Jo Guldi y David Armitage. ¿Cuál es el núcleo del texto? Los autores critican que la ciencia, la política y por extensión la historiografía contemporánea, se han sumergido en problemas de corto plazo, perdiendo el foco de los problemas más agudos que aquejan a las sociedades $y$, con ello, reduciendo su función social a cero, desde la ultra especialización que llena bibliotecas y revistas, pero poco y nada tiene que decir para el cambio social. Prueba de ello es que -argumentan Armitage y Guldi- los economistas se han transformado en los paladines del acontecer, son ellos en quienes los medios de comunicación confían para encontrar explicaciones del presente. Esto tiene su correlativo en dos aspectos esenciales: la ya dicha, para el caso de los historiadores, ultra especialización en temáticas muy específicas del pasado (con un alto manejo de fuentes, lo cual siempre se debe celebrar), y la otra, de mayor relevancia y relacionada con la anterior, el triunfo de la "corta duración" histórica como marco investigativo (Armitage y Guldi, 2016: 104). ${ }^{3}$

De la referencia: "La insistencia en los estudios de caso, los actores individuales y los actos del habla específicos desplazaron poco a poco los modelos de largo recorrido de Braudel, Namier, Mumford, Lovejoy y Wallerstein a favor de la microhistoria de Darnton, Davis y otros". Justo es decir que el texto presenta falencias importantes pues parece confundir, como muestra la cita, microhistoria con el estudio histórico en plazos cortos. Una crítica con respecto a esto en el artículo de Hunt como respuesta al libro, contenido en un dossier especial de Annales (Hunt, 2015). Lo que nos parece rescatable del libro es la necesidad de volver a pensar la larga duración y la función social de la historiografía hoy en día. 
No es posible entrar en este momento en la discusión de la función social del historiador y de las ciencias sociales en general, pero urge mencionar ciertas ideas, aunque sea de manera rápida, pues guardan directa relación con el problema de la larga duración que indicamos para la histórica de la muerte. Primero, que el llamado a volver sobre largas duraciones históricas es fundamental. Segundo, la apelación a la corta duración no puede quedar sobre un velo negativo, ella es siempre necesaria; con todo, debería existir cierto equilibrio entre lo micro y lo macro, sobre todo sin confundir el estudio del tiempo presente solo en base a estudios de corta duración. Problematizar el tiempo presente es pensar la(s) memoria(s) -muchas de ellas en pugnas-siempre desde narraciones de testigos en complementación con huellas documentales, lo cual no puede impedir una mirada en larga duración. Al fin y al cabo, el estudio de las memorias en conflicto se ha trasformado de manera global, según Henry Rousso, en una especie de nuevo derecho humano (Rousso, 2016: 10). Tercero, desde un plano más general, el sometimiento de la corta duración y la sobreespecialización son síntomas de un problema mayor, cual es que el siglo XX presentaría a nivel global, con el triunfo globalizado del sistema capitalista, la aceleración de la vida social y, con ello, una mutación en la conciencia histórica. En otras palabras, una nueva (no única) manera de comprender pasado, presente, futuro, las siempre presentes categorías temporales de todo sujeto. Tal fenómeno global está comenzando a ser estudiado: presentismo le llama François Hartog, lento presente le denomina Hans U. Gumbrecht, fascinación y abandono del pasado en la filosofía de Manuel Cruz, aceleración social desde la sociología crítica de Harmut Rosa. La hipótesis que se conjuga en las cuatro propuestas es que, a lo menos desde la segunda mitad del siglo pasado, en las sociedades parecen prevalecer el instante, el presente sin más, a lo más el futuro cercano, pero han renunciado al futuro como proyecto, como un telos generador de experiencia.

Visto así, y como formulación teórica, proponemos que la muerte, como fenómeno antropológico y social, al ser una experiencia social comunicada (vemos morir a nuestros semejantes a lo largo de la vida, hablamos de ello aunque sea poco, etc.), ya secularizada socialmente desde el siglo XVIII europeo y el siguiente en América, aparece en el siglo XX como un problema postsecular, es decir, como un fenómeno que ha perdido el sentido histórico que antes se le había atribuido, en relación a la tesis de Hans Blumenberg, de que las filosofías de la historia del siglo XX, todas hijas de su tiempo, chocan con la pérdida de evidencia y confianza en la historia (algo claro desde Nietzsche en adelante) luego del apogeo del historicismo decimonónico, pasando a una realidad muy distinta en el recorrido del siglo XX, lugar donde la historia como res gestae ha perdido el sentido que antes ostentaba (Palti, 2008: 32), sea éste el de historia magistra vitae o de la historia como herramienta en la proyección de futuros confiables. En este contexto es donde situamos, desde una posición teórica, el 
sentido social del morir. La impronta será, para efectos de este trabajo, pensar la muerte como problema temporal: estudiar la muerte es asumir cognitivamente nuestra existencia de manera teleológica (nacemos-morimos), pero las sociedades actuales tienden a socializar el instante, el placer del consumo, del bienestar, la seguridad a corto plazo, dejando de lado la problemática del futuro y con ello la del morir. Vista así, la muerte queda silenciada. Un análisis práctico y de corta duración no podría prestarse para un planteamiento como este, lo cual no quita su necesidad empírica. Este trabajo quiere ser un apoyo para su futura realización.

El viejo problema de la larga duración de procesos culturales no ha dejado ni puede dejar de ser discutido; a Braudel lo han querido soslayar, pero no es posible del todo. En lo que respecta este trabajo, sigo la propuesta del tiempo largo desde las agudas lecturas de Philippe Ariès, Michel Vovelle y Tony Walter, con base en una renovada teoría de la historia que se muestra en los últimos años como el conjunto de herramientas necesarias para la fundamentación historiográfica desde la reflexión analítica del trabajo historiador. ${ }^{4}$

Quisiera comenzar los argumentos desde un extracto de nuestra Violeta Parra:

Ya se va para los cielos ese querido angelito a rogar por sus abuelos por sus padres y hermanitos

Cuando se muere la carne el alma busca su sitio adentro de una amapola o dentro de un pajarito

La tierra lo está esperando con su corazón abierto por eso es que el angelito parece que está despierto

4 La teoría historiográfica se entiende hoy lejos de la normatividad decimonónica que se traspasó a buena parte del siglo XX. Ahora espera entenderse desde las discusiones de la filosofía de la ciencia de segunda mitad de siglo, toda vez que responde a las condiciones de posibilidad, siempre contingentes, de una disciplina que no ha dejado de aspirar a enunciados veritativos acerca del pasado. En palabras de Rüsen (2000: 68), desde la autorreflexión disciplinaria. 
Pocos podrán decir hoy en día que les parece familiar el poema de Violeta Parra, esto es por las mutaciones en el tiempo que ha tenido la historicidad del morir desde su sentido social hasta su misma territorialidad (enterramiento), por ejemplo, desde el paso de la Iglesia y sus alrededores al cementerio laico; del hogar al hospital; del hospital a la morgue; de la morgue a la comercialización de la tierra como espacio, símbolo incluso de diferencias sociales representadas en cementerios distintos unos de otros por su estatus comercial y social. La bella imagen del niño pequeño fallecido -horrorosa para otros - es el de la convivencia entre dolor, tristeza, resignación y festividad de familiares y vecinos del ser que ha muerto -lo que denominaremos para efectos de este escrito vestigios de la muerte barroca-, historicidad que escapa por mucho a la visión contemporánea del morir, cada vez más alejada de esa imagen comunitaria de la muerte, anclada en la visión de thánatos como derrota del cuerpo y de la técnica, la visión de la muerte moderna (Walter, 1994: 47-54)

La creencia popular que cantó Violeta nos remite al morir de un menor de siete años, a quien, una vez fallecido, se le asignaba una representación emocional desde el más allá. Desde la creencia católica de los ángeles guardianes y de la comunión de los santos, el niño que ha subido al cielo sin mancha (no se le considera pecador) ha pasado simbólicamente a ser un protector, una agente de rezos por la familia que aún queda en el mundo de los vivos, pues, al no tener manchas de pecado, no pasa por el Purgatorio (creencia europea que data del siglo XII y que llegó a América desde el siglo $X V$ ), ese lugar imaginado destinado a limpiar los pecados de quienes esperan la redención para estar en la presencia eterna del Dios cristiano. Esta creencia popular que las sociedades latinoamericanas mantuvieron desde antaño aún se mantiene pero, producto de la secularización de la vida social (que no es lo mismo a decir descristianización) y la separación de las esferas públicas y privadas (pensemos en el fenómeno de laicización desde el siglo XIX), fue quedando relegada a lo que parece ser hoy: una creencia en extinción.

El ejemplo del angelito nos sirve para recordar varias creencias populares en nuestra historia respecto de la muerte, y cuando digo "populares" me refiero a que las llevaron a cabo miles de hombres y mujeres sostenidamente en el tiempo, indistinto de su condición social: fundación de misas para acelerar el paso por el purgatorio, la creencia de la vida eterna y del infierno, la asociatividad ante la muerte en las cofradías, y la fundación testamentaria de capellanías de misas (fenómeno que, según ha demostrado la profesora María Eugenia Horvitz y su equipo, pervivió, para el caso de Chile, desde el siglo XVI hasta entrado el siglo XX) (Horvitz, 2004: 10), entre otras. Todas prácticas culturales desde los distintos estamentos desde sociedades tradicionales y que, una vez impactadas con la llamada modernidad, tomaron otros colores y otras formas, hasta llegar al siglo XX, momento en que la religiosidad de la muerte se vio fuertemente trasformada. 
Llegamos así al centro del problema de este trabajo, planteado por muchos intelectuales, y en donde quizás el más conocido a nivel mundial siga siendo Philippe Ariès y su macro temporalidad de la muerte en occidente. Desde Chile, y hace no mucho, Fernando Lolas, prestigioso médico psiquiatra de la Universidad de Chile, comentaba desde la antropología médica y sus relaciones con la ética (de la mano de Ariès) lo siguiente: "La historia de la muerte en Occidente muestra que ella ha pasado, del hecho íntimo, doméstico y natural a ser causa de confusión y sensación de fracaso, cuando no motivo de negación y rechazo, por demostrar la incapacidad de la técnica para solventar problemas perennes" (Lolas, 2006: 205).

Del sentido mítico y religioso del morir al sentido laico de las sociedades modernas hay un transcurrir histórico indudablemente ligado a las manifestaciones sociales con respecto a la muerte y de la cual la historiografía, las ciencias sociales y hasta la literatura pueden dar cuenta. El influjo de la salubridad como canon, la sobrevivencia de los recién nacidos (el aumento sostenido en la esperanza de vida), la tecnología farmacéutica y las vacunas, la medicina y su lucha constante contra la muerte, etc. Sumemos la llegada de las revoluciones científicas de siglo XVII, que no han cesado de sorprendernos, las ideas ilustradas, el liberalismo en todas sus etapas, el triunfo del libre mercado y del placer presentista del consumo, etc. Todos estos son fenómenos que nos hacen mirar las actitudes ante la muerte en el tiempo de una manera distinta. Ya no tanto desde las prácticas, asunto que la historiografía europea y latinoamericana bien han demostrado, sino que ahora pensar la muerte desde la temporalidad y las ideas: diacrónicamente. El microanálisis resulta imposible para tal objetivo, por lo que no parece quedar otra opción que sobre la base de arquetipos teóricos o "tipos ideales", al estilo weberiano. La "muerte invertida" Ilamó Ariès a las experiencias del morir moderno, en especial desde el siglo XX (Ariès, 1977: 261-286). Si en ella registramos un conector con las sociedades aceleradas y presentistas de nuestra contemporaneidad, en esa dirección camina nuestra propuesta.

Ahora bien, si seguimos a uno de los grandes teóricos de la historia de los últimos tiempos, Reinhart Koselleck, tendremos que asociar inevitablemente la llegada de lo que asociamos a la muerte moderna con un fenómeno de enorme valor que la historia conceptual nos ha legado: el tiempo tiene historicidad. En otras palabras, las sociedades presentan distintas formas de pensar las categorías pasado, presente y futuro. Siguiendo al historiador alemán, el uso de una serie de conceptos que venían usándose desde el siglo XVI toman fuerza y se proyectan como ideas fuerza desde el XVIII: liberalismo, socialismo, progreso, ciencia, revolución, etc., todos ellos ligados a lo que la semántica histórica viene trabajando desde la tesis kosellequiana de "conceptos creadores de experiencia" (Koselleck, 2012: 202; Fernández Sebastián, 2014). Quizás, la idea que mejor nos ayude es la de progreso, precisamente porque se transformó en un 
verdadero generador de expectativas, transformador de la experiencia temporal de las sociedades (Koselleck, 2012: 106); un nuevo régimen temporal asociado a mejorar la experiencia de vida de hombres y mujeres. El futuro comenzaba a esbozarse desde la esperanza en el bienestar, donde el Estado parecía poder proveer las condiciones que el Antiguo Régimen evidentemente no logró ofrecer. Esta confianza en el futuro debe entenderse, a lo menos, desde dos horizontes conceptuales y teóricos: como modernidad, que corresponde a la autodeterminación política y a la autonomía moral, y como modernización, al proceso técnico de control de la naturaleza desde el cálculo racional (Lechner, 1990), control y confianza que no comulgaron con la idea del morir.

Para comprender el proceso de modernización del mundo occidental desde el problema de la temporalidad, en el que la secularización de la vida guarda directa relación con la problemática de la muerte, es necesario ocupar las nociones de "campo de experiencia" y "horizonte de expectativas" (Koselleck, 1993: 333-357). Estos dos conceptos metahistóricos son la posibilidad de toda historia en cualquier tiempo y lugar. Son las herramientas que tiene el historiador para asomarse a las distintas experiencias sociales, pues todo sujeto las ocupa cognitivamente en su devenir. No se trata de una medición de la temporalidad lineal, sino más bien de una fenomenología del tiempo muy similar a la tesis de Agustín de Hipona que luego complementó Paul Ricoeur desde la filosofía del lenguaje, en la que pasado y futuro solo pueden comprenderse desde la consumación del presente. En esta línea hermenéutica Koselleck propone que, tanto el campo de experiencia -que no es más que el pasado y su repercusión en el presente- y el horizonte de expectativas -la proyección de espera y la idea de futuro de cualquier acción humana- puedan utilizarse como herramientas heurísticas para comprender que lo que cambia y lo que se genera como novedoso no son más que constructos sociales que coexisten simultáneamente de modo no excluyente (Fernández Sebastián, 2014: 22). Esto es lo que creemos pasa con la muerte modernizada.

Otro argumento que refuerza lo dicho es la relación sujeto-naturaleza. La modernidad es para muchos autores la objetivación de la naturaleza y la subjetivación del ser humano, lo que devino en entidades totalmente separadas (Díaz, 2015: 156). Pensemos en el proyecto llustrado precisamente como la posibilidad de mejorar la naturaleza para el bienestar del ser humano desde el progreso. El barroco como comprensión social desde sus múltiples manifestaciones consistió precisamente en lo contrario, en un entendimiento o esfuerzo por comprender conjuntamente naturaleza y humanidad, por lo mismo la muerte barroca -como explica la tesis de Isabel Cruz- puede entenderse como la victoria de lo humano sobre la finitud carnal (Cruz, 1997: $X X X)$. Las pompas, el boato, las misas y la festividad de la muerte sociabilizada, que contrasta con la muerte contemporánea arrojada al hospital, a la técnica (triunfo o derrota de la medicina), al cada vez más pequeño grupo 
familiar, evidencian un triunfo psicológico desde una comprensión escatológica y teleológica del tiempo. La muerte barroca es, puesta bajo el alero de una comprensión lineal del tiempo histórico marcada por la parusía, aquello que se testaba en la cláusula "poner el alma en carrera de salvación". En contraste, la muerte secular de nuestra contemporaneidad parece estar regida bajo otras lógicas (incluso mercantilistas), todas las cuales podrían tener comprensión bajo una interpretación social del tiempo distinta del tiempo escatológico cristiano, donde pasado, presente y futuro cobran experiencia bajo la fuerza del presente, del instante.

Tony Walter parte su análisis desde la muerte tradicional, tipo ideal que asocia a una serie de variables que predominaron hasta el siglo XIX y que se resumen en actitudes de dolor y aceptación ante la muerte producto, principalmente, de la creencia en el más allá, desde la autoridad de la creencia en un ser superior. A lo tradicional, Walter opone el advenimiento de la muerte moderna desde finales del siglo XIX y neomoderna desde el XX. La medicina y la técnica aparecen como fundamentales para el análisis, pues toman el rol de autoridad que antes tenían los grupos religiosos, también la separación de lo público y lo privado, la técnica, el "olvido" de la muerte por no convivir con ella a diario; a diferencia del tipo tradicional y la impronta de una suerte de individualidad que parece superponerse a la autoridad médica (Walter, 1994: 47-68).

Ariès entrega una serie de diferencias históricas para lo que Walter entiende como muerte tradicional, compartiendo muchos puntos de análisis. Desde el siglo XI hasta el XIX, Ariès entiende tipologías de actitudes ante la muerte que denomina la muerte domada, la propia muerte, la muerte vedada y la muerte del otro (2000: 23-101). Coinciden ambos autores en que el siglo XX es el momento de los grandes cambios, producidos desde el siglo XIX, observándose una menor comunicación del morir, la declinación del sentir religioso ante la finitud y una especie de tabú y silencio ante un problema del que no se quiere hablar ni enfrentar.

Las actitudes contemporáneas ante la muerte Ariès las llamó la "muerte invertida", Edgar Morin expresó una "crisis de la muerte" (Morin, 1994: 297), Geoffrey Gorer la denominó como un "tabú" (Gorer, 1965: 169-175); David Moller la explicó con la metáfora de la muerte como un "congelador de silencio" (Moller, 1996: 21) y Tony Walter, como he dicho, diferencia muerte moderna y neomoderna. Coinciden todos en una resignificación de la muerte entendida desde dos fenómenos: la secularización de la vida, que ha hecho de la razón y la fuerza humana el motor del progreso, en donde hay menos cabida para visiones de mundo con imágenes celestes, purgatorios e infiernos ardientes; y de una naturalización del morir desde un prisma biológico y médico (técnico). 
También la filosofía tiene algo que decir al respecto. En Platón y su teoría del alma tripartita -el intelecto, la ira y la concupiscencia- ya se observa la creencia de que todo hombre debe aspirar a un equilibrio entre las fuerzas del alma para alcanzar la región celeste, donde habita la verdad; idea recuperada con el pasar de los siglos para fundamentar la idea de salvación del alma, problema tan fundamental en la visión de la muerte barroca y tradicional. Para los filósofos clásicos la muerte significaba liberación. La tradición escolástica cristina convirtió la visión antigua de la muerte en devenir escatológico. Tiempo de la espera para la vuelta al lugar de origen, al creador; asunto que debía ganarse y que quedó transcrito en miles de testamentos hispanoamericanos desde el Medioevo. Nietzsche es considerado el filósofo que rompe con la tradición metafísica pues para él no hay nada más que la vida, la existencia es lo real, desde la afamada frase "Dios ha muerto" llamaba a la preocupación por la recuperación de la vida, del mundo. Con el filósofo alemán comienza un nuevo recorrido del pensamiento ligado a su propia historicidad y que podemos sintetizar en la pérdida de la certeza kantiana y el nacimiento del llamado "pensamiento débil", contrario al cogito cartesiano que todo parecía alcanzarlo y comprenderlo. La verdad queda así situada contextualmente, ya no es un ideal en el cual se crea de manera metafísica. Nietzsche, en sus Consideraciones intempestivas, critica el régimen moderno de historicidad que tanta fuerza tomó desde el historicismo. El siglo XIX es el triunfo de la Historia como "singular colectivo", según la famosa frase de Koselleck. Su filosofía, la de Nietzsche, es un conjunto de luces de un fenómeno que un siglo después será una realidad: la pérdida de confianza en la Historia producto de la llamada caída de los metarrelatos, y con ellos, de la confianza del devenir humano hacia el progreso. La conciencia histórica del siglo XX nos da cuenta de una "pérdida de evidencia" (Hartog, 2005: 267-293) a lo menos desde la interpretación optimista del historicismo. Un nuevo régimen de historicidad (comprensión social de las tres categorías temporales) comenzaba a gestarse según la ya famosa tesis de François Hartog, la tesis del presentismo (Hartog, 2003).

Este pequeño repaso por el pensamiento occidental de las actitudes ante la muerte tiene una enorme relación con el sentir del morir contemporáneo, un sentir asociado a la técnica, al pensamiento laico y, al parecer, menos comunicado que en otros tiempos, menos hablado (lo cual no implica necesariamente menos religioso). Las representaciones del mundo tradicional (premodernas), y con ellas las del morir, parecen hablar de cierto equilibrio entre vida, experiencia y final biológico (finalmente de la muerte nadie se escapa). La certeza de la muerte tenía, de algún modo, un sentido histórico, por tanto, temporal. La pregunta por el sen- 
tido histórico obedece al trabajo teórico de los presupuestos abstractos y prácticos de la disciplina científica en la cual creemos. En esta línea, Jörn Rüsen expresa: "El sentido histórico es tiempo interpretado, integrado en la orientación y la motivación de las acciones humanas, y puesto de relieve en la manera y la medida del sufrimiento humano" (Rüsen, 2013: 44). ¿En qué medida este postulado nos sirve de argumento? La centralidad temporal, no sincrónica sino diacrónica para la historia en larga duración, es la llave de acceso a un planteamiento nuevo. Las actitudes ante la muerte pueden ser así interpretadas desde la comprensión temporal de las tres categorías temporales de la conciencia humana: pasado, presente y futuro, problemática que desde la filosofía de la Grecia clásica viene motivando a pensadores como Aristóteles, San Agustín, Kant, Heidegger, Husserl y al filósofo francés Paul Ricoeur, también a historiadores, el ya citado Koselleck y Hartog están siendo altamente valorados desde la reflexión disciplinar.

Desde Ricoeur tomamos posición. La relación de pensar el morir con su propuesta desde la filosofía del lenguaje (los tres tomos de Temps et récit, publicados entre 1983-1985) lo he desarrollado en otro momento (Ovalle, 2012; Ovalle, 2013), solo repetir aquí para el lector que la propuesta ricoeuriana es atingente para cualquier historiador abierto a nuevas herramientas historiográficas. Ricoeur intenta dar comprensión a la pregunta sin respuesta ¿qué es el tiempo? El tiempo para Ricoeur no es aprehensible, no lo podemos observar directamente. Nos queda la única opción de la narración, del relato ficticio y/o verdadero. Un desvío hermenéutico que aspira a la comprensión y explicación de los fenómenos humanos. La narración es la que entrega claridad a la experiencia temporal: "el trabajo de pensamiento que articula toda configuración narrativa termina en una refiguración de la experiencia temporal" (Ricoeur, 1985: 9). Mediante la mimesis aristotélica Ricoeur intenta dar lógica a la temporalidad humana (prefiguración, configuración y refiguración/ mimesis 1,2 y 3 respetivamente), problema que también he trabajado historiográficamente (Ovalle, 2011). Más importante para nuestro objetivo resulta la doble salida, propuesta por Ricoeur, al enfoque fenomenológico (el tiempo íntimo, personal) y trascendental (tiempo cósmico) mediante conectores de temporalidad bien establecidos: el calendario, la noción de generación (coexistencia de generaciones, siguiendo a Mannheim) y el concepto de "huella" (los documentos históricos, la epistemología de la historia). Todas ellas y sus conexiones le permiten al filósofo francés establecer un tercer tiempo, ya no fenomenológico ni cosmológico: el tiempo histórico. Los historiadores son los responsables de este tercer tiempo, o por lo menos a ellos Ricoeur les confía esa tarea de veracidad, o como expresó de mejor forma al iniciar la XII Conferencia Marc Bloch del año 2000, como "el pacto de verdad entre historiador y lector", y que 
trabajó con más detalles al publicar La memoria, la historia, el olvido. ${ }^{5}$ Como recuerda su biógrafo intelectual: "Paul Ricoeur ubica pues el discurso histórico en una tensión que le es propia, entre identidad narrativa y ambición de verdad" (Dosse, 2013: 520). Narración como vehículo de la temporalidad, que en nada se acerca a las tendencias "narrativistas" de la historiografía, las cuales debemos asociar a nombres como Hayden White y Frank Ankersmit.

Con la llegada del siglo XX, Occidente ha venido mutando estas representaciones del mundo, en las cuales la experiencia del tiempo también ha mutado y con ella las actitudes ante la muerte. La secularización de la vida y la búsqueda del bienestar en un progreso inconmensurable desde el placer, el consumo y el éxito ininterrumpido de necesidades en constante transformación (más allá de las necesidades básicas para la subsistencia), han transformado las sociedades (ahora globales) y sus modos de pensar el fin de la existencia. La verdad ya no es tal y la relación entre pasado y futuro o entre, citando a Koselleck, experiencia y expectativas se ha roto. Las expectativas se han hecho siempre presentes (presentismo) y la rapidez de los cambios tecnológicos nos empujan a sentir que el tiempo se acelera y que el futuro ya llegó. Distinta percepción de la moderna experiencia del tiempo en la que, de la mano del progreso y el desarrollo tecnológico, el futuro parecía esplendoroso, por lo menos eso esperaba la ciencia, la filosofía y la política.

Para finalizar, trazamos la pregunta fundamental. Lo hacemos al final pues estas líneas esperan promover la investigación, en ningún caso cerrar la problemática: desde una mirada teórica y aproximativa, ¿tiene sentido histórico la muerte en nuestras sociedades contemporáneas? Desde los tipos ideales weberianos y desde las peligrosas generalidades, pareciera que menos que en comparación con siglos anteriores. Si hacemos eco de esta especie de hermenéutica de la temporalidad, tendremos que decir que a la muerte en las sociedades tradicionales occidentales, hasta el siglo XIX, se le asignaba cierta conciencia histórica. La vida y la experiencia se proyectaban en la salvación, en la muerte como un paso hacia algo más. Desde la secularización de la vida, desde los avatares de la razón (pasando por Kant, Descartes, Nietzsche o Derrida y otros), desde la llegada de la técnica, la medicina y al consumo como modo de vida, las experiencias se comprimen en un presente perpetuo, en el que la muerte genera incomo-

"El problema de la representación del pasado por los historiadores puede enunciarse en términos de un pacto tácito que se establece entre el lector del texto histórico y el autor. El primero espera que se le proponga un 'relato verdadero' y no una ficción. El segundo tiene entre manos el problema de saber si la escritura de la historia puede respetar ese pacto, cómo puede hacerlo y hasta qué punto" (Ricoeur, 2000: 734). 
didad. Pareciera que la muerte barroca sí tenía un sentido histórico, de la que en esta segunda modernidad (líquida) adolece. No se trata de añorar un sentido histórico perdido. Más bien de hacer presente la famosa frase de Marc Bloch: el pasado tiene que comprenderse por el presente y viceversa.

Byung-Chul Han, filósofo contemporáneo, no cree en la aceleración de la vida social (crítico de Rosa), pero sí en la percepción de que el tiempo ya no se comprende de la misma forma que hace unos cincuenta años: "Hoy en día, la sociedad (...) se caracteriza por la desaparición de la otredad y la extrañeza" (Han, 2012: 13-14). El autor opone a la falta de sentido de otredad la idea de diferencia: "A la diferencia le falta, por decirlo así, el aguijón de la extrañeza (...) también la extrañeza se reduce a una fórmula de consumo. Lo extraño se sustituye por lo exótico y el turista lo recorre" (Han, 2012: 14). Desde la discusión del paradigma "inmunológico" como metáfora para entender el mundo actual (en lo cual no podemos detenernos acá), el filósofo dirige la mirada hacia lo que llama "exceso de positividad, lo cual determina la abundancia de lo idéntico" (Han, 2012: 19). Esa positividad nuestro autor la observa en la "superproducción", el "superrendimiento" y la "supercomunicación", signos ineludibles del presentismo en Hartog (Hartog, 2003:101).

La reflexión filosófica de Han ayuda a pensar el morir actual en otro término. Como hemos dicho, si pensar la muerte es por así decirlo un problema temporal por corresponder a la finitud existencial, la reflexión de la historicidad del devenir humano en términos temporales nos conduce hacia el camino correcto. Han ofrece una posibilidad en un segundo texto: el mundo actual presenta una "dispersión temporal", una disincronía que es el resultado de la atomización del tiempo (Han, 2015: 9). En sus palabras: "la pobreza del mundo es una aparición discrónica. Hace que la gente se encierre en su pequeño cuerpo, que intenta mantener sano por todos los medios, porque, de lo contrario, uno se queda sin nada. La salud de su frágil cuerpo sustituye al mundo y a Dios. Nada perdura más allá de la muerte. Hoy en día, morir resulta especialmente difícil. La gente envejece sin hacerse mayor" (Han, 2015:10). El análisis someramente expuesto es funcional a los síntomas de la realidad global en términos teóricos, pero no compartimos el fondo de la propuesta del filósofo surcoreano. La vida misma es en sí teleológica, y su filosofía apunta al despojo de cualquier teleología. Aboga por una revalorización de la vida contemplativa, asunto que no podemos discutir por no ser atingente a nuestro propósito, aunque su propuesta resulta funcional, repetimos, al problema de la historicidad del morir contemporáneo.

Lo cierto es que esta disincronía ha desequilibrado la conciencia temporal de los sujetos y, con ello, el del sentido histórico de la muerte. 
Byung-Chul Han acude a filósofos clásicos para sustentar este desequilibrio: "Tanto la muerte libre y consumadora de Nietzsche como el ser libre para la muerte de Heidegger responden a una gravitación temporal, que se ocupa de que el pasado y el futuro comprendan, abarquen el presente. Esta tensión temporal desliga al presente de su huida infinita y sin rumbo y lo carga de significación, (...) en cambio en un tiempo atomizado, todos los momentos son iguales entre sí (...). De ahí que hoy resulte especialmente difícil morir" (Byung-Chul Han, 2015: 15-16). Este proceso cultural de la destemporalización del mundo, que para Harmut Rosa es resultado de la aceleración social, para Byung-Chul Han corresponde a la pérdida del sentido histórico. Han no está de acuerdo con el sociólogo alemán, y no estamos en condiciones de discutirlos ni de buscar una salida intermedia. Lo que importa para el objetivo de este trabajo es la desorientación del tiempo en las sociedades tardo-modernas o posmodernas y postseculares. Sea sensación de aceleración o sin sentido, lo cierto es que el presentismo de hoy hace perder sentido al "pasado en el presente" y a los "futuros pasados". El morir es un problema del futuro.

Con todo, los trabajos de Manuel Cruz iluminan también este proceso social y global de que, de alguna manera, le hemos dado vuelta la espalda a la historia y, con ello, hemos caído en un desequilibrio de las categorías temporales pasado, presente y futuro. Todo lo cual nos permite sostener el sin sentido del morir actual como respuesta a un fenómeno narrativo, por tanto, temporal. El presentismo, del cual la historicidad de la muerte contemporánea es parte, asume un proyecto de investigación en el que la historia en larga duración es fundamental. Finalmente, cómo no tomar nota del llamado de atención del filósofo catalán cuando expresa: "La vida actual, desde el momento en que renunció a la historia, perdió la posibilidad de concluirse con sentido" (Cruz, 2016: 74). La tarea del historiador sigue siendo el estudio del pasado, pero desde y para el presente que observa, vive y padece. Finalmente, ¿acaso la muerte no es la extrañeza total? Nos parece que este conjunto de excesos que presenta la sociedad globalizada, que Han llama la "sociedad del rendimiento" -la misma que no puede con tanta carga y termina siendo la sociedad del cansanciorepele el morir, no lo acepta, por tanto, no lo comunica. Ese devenir de las actitudes ante la muerte debe ser historizado en larga duración, y se nos presenta, a los historiadores, como nueva oportunidad para la historia del tiempo presente. 


\section{Referencias bibliográficas}

\section{a) Artículos y capítulos de libros}

Díaz, J. J. (2015). "La experiencia de la modernidad como una experiencia barroca", en Historia Crítica, N 56, abril-junio.

Fernández Sebastián, J. (2014). "Historia, historiografía, historicidad. Conciencia histórica y cambio conceptual", en Europa del sur y América Latina. Perspectivas historiográficas. Madrid: Biblioteca Nueva.

Gorer, G. (1965). "The Pornography of Death", en Death, Grief and Mourning in Contemporary Britain. London: Cresset.

Hartog, F. (2003). "Órdenes del tiempo, regímenes de historicidad", en Historia y Grafía. № 21, pp. 73-102.

Hunt, L. (2015). "Does History Need a Reset?", en Annales (English Edition), N 70 (2), pp. 249-254.

Lechner, N. (1990). “ ¿Son compatibles modernidad y modernización? El desafío de la democracia latinoamericana". Documento de Trabajo, FLACSO-CHILE, N 440, marzo.

Ovalle, D. (2011). "Le travail de la memoire en Paul Ricœur: la significación como aporte epistemológico para el estudio de la Historia", en Historia 396, Volumen I: No 2, pp. 265-280.

Ovalle, D. (2012). "El paso de la muerte narrada a la muerte callada en Chile siglos XVI - XIX. Reflexiones para una hermenéutica de la muerte", en Cuadernos de Historia Cultural, N 1, pp. 22-39.

Ovalle, D. (2013). "Narración, tiempo humano y muerte: reflexión teórica para una hermenéutica histórica de la muerte", en Historia Autónoma, № 2, pp. 161-175.

Palti, E. J. (2008). "Pensar históricamente en una era postsecular. O el fin de los historiadores después del fin de la historia" en El fin de los historiadores. Pensar históricamente en el siglo XXI. Madrid: Siglo XXI.

Ricoeur, P. (2000). "L'ecriture d' histoire et la représentation du passé", en Annales, $N^{\circ} 55$, p. 4.

Ricoeur, P. (2010). "La distancia temporal y la muerte en historia", en Historicidades, Buenos Aires: Waldhuter.

Rüsen, J. (2000). "Origen y tarea de la teoría de la historia", en Debates recientes en la teoría de la historiografía alemana. México: UAMA. 


\section{b) Libros}

Ariès, P. (1977). L'Homme devant la mort. París: Seuil.

Ariès, P. (2000). Historia de la muerte en Occidente. Desde la Edad Media hasta nuestros días. Barcelona: El Acantilado.

Armitage, D. y J. Guldi (2016). Manifiesto por la Historia. Madrid: Alianza.

Aróstegui, J. (2004). La historia vivida. Sobre la historia del presente. Madrid: Alianza.

Cruz, I. (1997). La muerte. Transfiguración de la vida. Santiago: Ediciones UC.

Cruz, M. (2016). Ser sin tiempo. Barcelona: Herder.

Dosse, F. (2013). Paul Ricoeur. Los sentidos de una vida (1913-2005). Buenos Aires: Fondo de Cultura Económica.

Gadamer, H. G. y R. Koselleck (1997) Historia y hermenéutica. Barcelona: Paidós. Han, B. (2012). La sociedad del cansancio. Barcelona: Herder.

Han, B. (2015). El aroma del tiempo. Un ensayo filosófico sobre el arte de demorarse. Barcelona: Herder.

Hartog, F. (2005). Évidence de l'histoire. Ce que voient les historiens. París, Ed. EHESS.

Koselleck, R. (1993). Futuro pasado: para una semántica de los tiempos históricos. Barcelona: Paidós.

Koselleck, R. (2001). Los estratos del tiempo: estudios sobre la historia. Barcelona: Paidós.

Koselleck, R. (2012). Historia de conceptos. Estudios sobre semántica y pragmática del lenguaje político y social. Madrid: Trotta.

Lacapra, D. (2009). Historia y memoria después de Auschwitz. Buenos Aires: Prometeo.

Moller, D. (1996). Confronting Death. Values, Institutions \& Human Mortality. Oxford: Oxford University Press.

Paul, H. (2015). Key Issues in Historical Theory. New York: Routledge.

Rüsen, J. (2013). Tiempo en ruptura. México: UAMA.

Walter, T. (1994). The Revival of Death. Londres: Routledge. 